\title{
Thoracoscopic Surgery for Posterior Mediastinal Mass: Our Initial Experience
}

\author{
Ranjan Sapkota, ${ }^{1}$ Prakash Sayami ${ }^{1}$ \\ ${ }^{1}$ Department of Cardio-Thoracic and Vascular Surgery Institute of Medicine, Tribhuwan University, Kathmandu, Nepal.
}

\begin{abstract}
Background: Thoracoscopic surgery has been increasingly used for a variety of indications. Posterior mediastinal tumors form an important component of a thoracic surgeon's workload. This report represents a summary of our initial experience in thoracoscopic management of such tumors. Methods: We retrospectively reviewed the clinical and operative data from records over the study period. We also describe our usual perioperative management and surgical techniques. Results: A total of 11 patients, 8 being females, were operated during the period of 30 months. Seven were incidental findings, and chest pain was the commonest presentation in symptomatic patients. The mean age of the patients was 38.7 years; mean tumor diameter was $4.4 \mathrm{~cm}$; eight had benign schwannoma, and no patient had a malignant tumor. Mean operative duration was $175.5 \mathrm{~min}$; there were no conversions and no transfusion was required. Mean length of stay in the hospital was 5.6 days. There were no perioperative deaths or major complications. Three minor complications were recorded. Follow-up (4 to 18 months) was uneventful. Conclusions: Thoracoscopic management of posterior mediastinal tumors is feasible and safe.
\end{abstract}

Keywords: neurogenic tumor; posterior mediastinum; thoracoscopic Surgery.

\section{INTRODUCTION}

The last decade of the last century saw a great leap of progress of thoracoscopic surgery. Until then it was essentially limited to treatment of pneumothoraces, bullae and non-anatomic lung resections. ${ }^{1}$ Continuous innovations in tools, techniques and tricks gradually brought thoracoscopy to the forefront of most of the thoracic procedures. The progress made in pulmonary resections also paralleled that in mediastinal surgeries. Unprecedented exposure of the whole ipsilateral mediastinum, versatility of movements and significant reduction of access trauma make it particularly useful in mediastinal surgeries. As such, after the first report of a thoracoscopically removed posterior mediastinal mass in 1992 by Landreneau, it has established itself as a reasonable alternative to thoracotomy for lesions of the posterior mediastinum. ${ }^{2,} 3$ This paper will summarize our initial experience in the use of thoracoscopy for posterior mediastinal mass at a few hospitals, primarily Manmohan Cardiothoracic Vascular and Transplant center.

\section{METHODS}

A retrospective review was done, spanning a period between March 2016 and October 2019, of patients who underwent thoracoscopic excision of their posterior mediastinal masses in four different hospitals by the same surgeons. From patients' records, essential preoperative profile, operative details and postoperative information were retrieved, observed and analyzed, and relevant literature reviewed.

Preoperative evaluation: All patients, either incidentally diagnosed or symptomatic, were evaluated with a standard set of tests. In both the groups, a chest $\mathrm{x}$-ray would usually suggest the possibility of a mediastinal mass. A contrastenhanced computed tomogram (CECT) of the chest would usually follow (Figure 1). Essentially, a posterior mediastinal mass was a CECT-based diagnosis. For all the masses thus visualized, a magnetic resonance imaging (MRI) of the chest followed, to better evaluate the tumor, its relations and its intraspinal extension. In both, features such as size, location, contiguous relation, bone erosion, loss of fat planes, extension into spinal canal, presence of pleural effusion and 'other' pleural lesions were specifically sought for. An imageguided needle aspiration or trucut biopsy would generally be avoided for a number of reasons: technical difficulty due to peculiar location,

Correspondence: Dr. Ranjan Sapkota, Manmohan Cardio-Thoracic Vascular and Transplant Center, Institute of Medicine, Tribhuvan University, Kathmandu, Nepal. Email: ranjansapkota@gmail.com. Phone: +977-9851135495. DOI: $10.3126 /$ jcmsn.v15i2.24174. Article Received: 2019-1-16. Article accepted: 2019-06-12. 


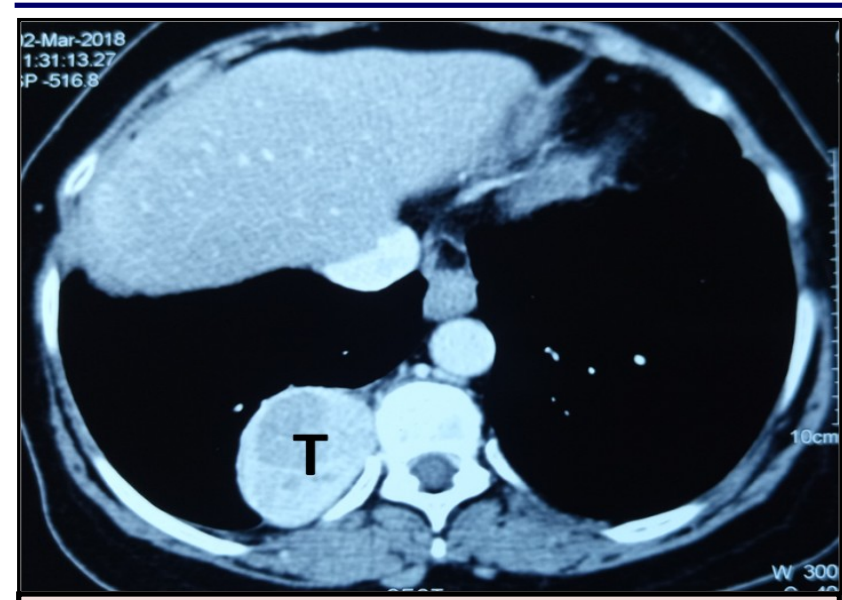

Figure 1. CECT chest showing a typical posterior mediastinal neurogenic tumor. Histology revealed benign schwannoma. $T$ : tumor

generally vascular nature of these tumors, insufficient material for confirmatory diagnosis because of relative acellularity of these tumors, and also, a general agreement on excision biopsy firsthand. ${ }^{4}$ Anesthetic fitness would be ensured, including an adequate lung function to allow singlelung ventilation.

\section{Anesthesia and Positioning}

A double lumen tube would provide the desired operative field with the lung adequately collapsed. Its final position would always be confirmed with a fibreoptic bronchoscope after positioning. It would be a full lateral decubitus position with the body rotated slightly anteriorly (so that the lung falls away), and the table bent to $45^{\circ}$ at a level slightly

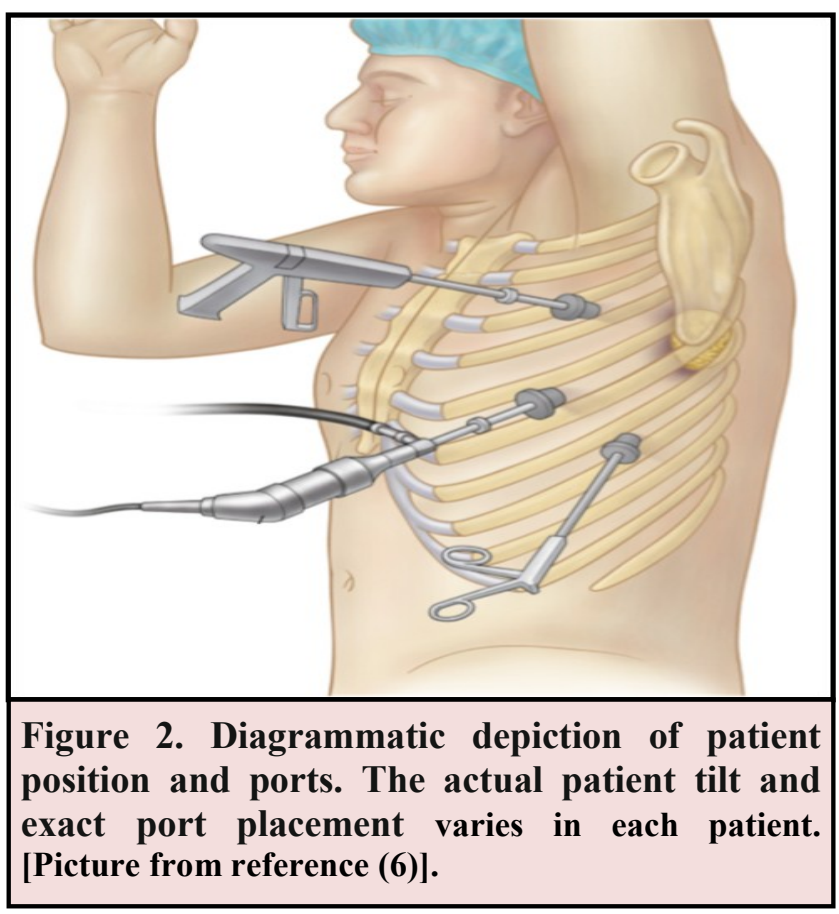

below the nipples, to open up the intercostals spaces (Figure 2). Invasive blood pressure, ECG, pulse oximetry, end-tidal $\mathrm{CO} 2$, airway pressure and ventilator volumes were routinely monitored and optimized. A central line catheter and an epidural catheter were infrequently used.

Instrumentation: An instrument set for urgent conversion to thoracotomy would always be available in the room. Unlike anterior mediastinal procedures, the wide space created by a collapsed lung would generally preclude the use of both, $\mathrm{CO}_{2}$ insufflation or valved ports. For ease of handling and cost-effectiveness without loss of efficiency, conventional thoracic instruments were used when possible. Similarly, conventional laparoscopic instruments, readily available, were used. Curved instruments, like the curved-tip monopolar electrocautery hook, curved atraumatic suckerdissector and curved sponge-holders made dissection easy. A $10-\mathrm{mm} 30^{\circ}$ Karl-Storz telescope and compatible video-system (Karl Storz, Tuttlingen, Germany) were used in all.

\section{Ports and Procedure}

The surgeon would always stand anterior to the patient, and ports would be placed to comply with that requirement. Realizing the well-known versatility of port-placement in thoracoscopic surgery, each case was dealt with individually, considering patient's body habitus and location of the lesion. However, a general pattern was followed. Three $10 \mathrm{~mm}$ ports were used in all the patients. The first port would usually be slightly posterior to the anterior axillary line at the $5^{\text {th }}$ (or $6^{\text {th }}$ ) intercostals space (ICS), establishing initial thoracoscopic view and subsequently guiding the other two. The second and third ports would be placed at the $3^{\text {rd }}$ (or $4^{\text {th }}$ ) ICS and $7^{\text {th }}$ (or $8^{\text {th }}$ ) ICS, posterior to the midaxillary line. (Fig 2) In females, ports could be slightly altered so as not to enter the breast. These ports generally followed triangulation principle to avoid 'fencing' and fell within the same $180^{\circ}$ arc to avoid mirror-imaging. Telescope and the instruments were exchanged between ports as necessary. A careful inspection of the tumor and the whole pleural space would generally be the first step (Figure 3).

An improvised 'bag' of a large surgical glove was used to retrieve the specimen at the end. The tumor was generally extracted through the most anterior port as the ICS is the widest anteriorly. The tumor bed was routinely inspected and hemostasis ensured. Where possible, an extrapleural catheter for postoperative analgesia would be inserted under vision. If however, because of the pleural loss/ breach this catheter could not be the best choice; multiple intercostal nerves were blocked under vision using $0.25 \%$ Bupivacaine. Finally, the lung 
was inflated under vision over a $28 \mathrm{Fr}$ chest tube placed basally and brought out through the inferior port which was then closed in layers, as with the other ports. Patients were extubated at the end of the procedure and transferred to intensive care units for subsequent monitoring, analgesia, physiotherapy and care. Typically they would leave ICU for general ward the following day. The chest tube, functional and without air leak, would be removed when a 24-hour output, serous or serosanguinous, was less than $100 \mathrm{ml}$, with a fully

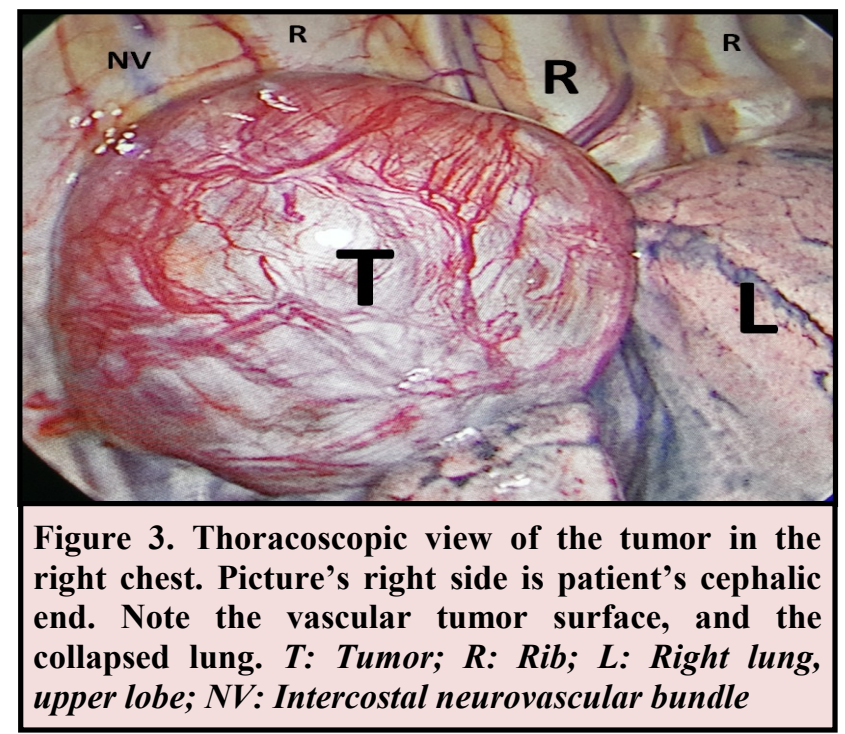

inflated lung on chest x-ray. Patients would be discharged when they were fully ambulatory, tolerating pain with oral analgesics and resumed a near normal diet.

\section{RESULT}

A total of 11 patients with posterior mediastinal tumors were managed during the period. Pertinent clinical and operative details are summarized in
Table 1. Majority (8/11) were females. Patients ranged from 18 years to 63 years (Mean 38.7). Seven out of 11 were incidentally diagnosed. All of the symptomatic patients had chest pain as their primary symptom. Average tumor size was $4.4 \mathrm{~cm}$ (range: 3.5-7). Nine had a right sided lesion. One of the patients had been subjected to multiple unsuccessful attempts at CT guided biopsy in the referring hospital. None others had an imageguided procedure preoperatively. Eight of the 11 lesions were located below the level of azygous/ arch. One (Patient 5; Table 1) had an intraspinal component (dumb-bell). On an average, it took 175.5 min (range: 90-300) for the procedure to finish (163 min for the 'non-dumb-bell' tumors only). None required conversion or blood transfusion. One of the tumors (Patient 10; Table 1) had a broad base and the portion near the neural foramen had to be left behind for fear of intractable bleed. The bronchogenic cyst (Patient 3; Table 1) was densely adherent to the left atrium and a centimeter-wide base had to be left behind and curetted. Histopathological evaluation showed that ten of the tumors were neurogenic, and 8 of ten: schwannoma (Figure 4).

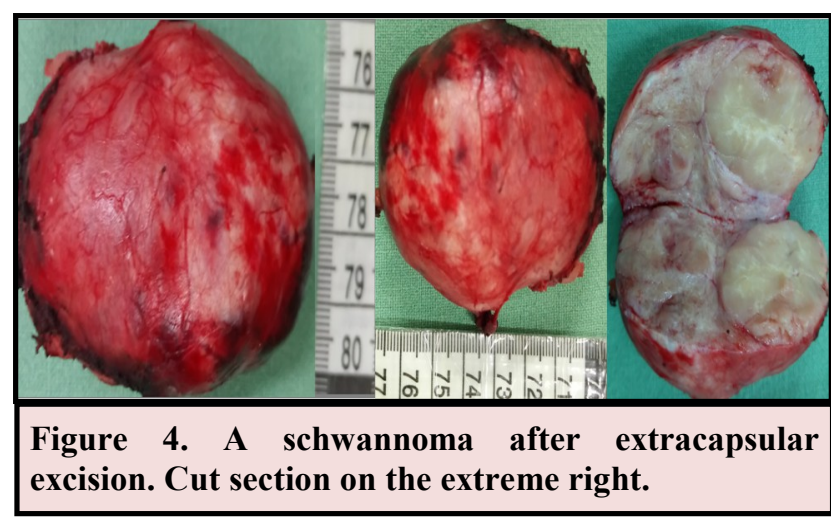

\begin{tabular}{|c|c|c|c|c|c|c|c|c|c|}
\hline $\begin{array}{l}\text { Pa- } \\
\text { tient }\end{array}$ & $\begin{array}{l}\text { Age } \\
(y r) / \\
\text { Sex }\end{array}$ & $\begin{array}{l}\text { Primary } \\
\text { symptom } \\
\text { (duration in } \\
\text { months) }\end{array}$ & $\begin{array}{c}\text { Largest } \\
\text { diame- } \\
\text { ter }(\mathrm{cm})\end{array}$ & Side & Consistency & $\begin{array}{l}\text { Post-op his- } \\
\text { tology }\end{array}$ & $\begin{array}{c}\text { Duration } \\
\text { of surgery } \\
\text { (min) }\end{array}$ & $\begin{array}{c}\text { Post-op day } \\
\text { of chest tube } \\
\text { removal }\end{array}$ & $\begin{array}{c}\text { LOS } \\
\text { (days) }\end{array}$ \\
\hline 1 & $33 / F$ & Incidental & 4 & $\mathrm{R}$ & solid & Schwannoma & 90 & 2 & 4 \\
\hline 2 & $18 / \mathrm{M}$ & Incidental & 5 & $\mathrm{R}$ & Solid & Paraganglioma & 180 & 2 & 4 \\
\hline 3 & $40 / \mathrm{M}$ & Chest pain (12) & 3.5 & $\mathrm{R}$ & pultaceous & $\begin{array}{c}\text { Bronchogenic } \\
\text { cyst }\end{array}$ & 170 & 3 & 5 \\
\hline 4 & $63 / \mathrm{F}$ & Chest pain (6) & 7 & $\mathrm{R}$ & solid & Schwannoma & 180 & 2 & 5 \\
\hline 5 & $29 / F$ & $\begin{array}{l}\text { Chest and back } \\
\text { pain (5) }\end{array}$ & 4 & $\mathrm{~L}$ & solid & Schwannoma & 300 & 3 & 5 \\
\hline 6 & $22 / \mathrm{F}$ & Incidental & 3 & $\mathrm{R}$ & solid & Schwannoma & 190 & 2 & 4 \\
\hline 7 & $42 / F$ & Incidental & 4 & $\mathrm{R}$ & solid & $\begin{array}{l}\text { Ganglioneu- } \\
\text { roma }\end{array}$ & 160 & 3 & 6 \\
\hline 8 & $37 / \mathrm{F}$ & Incidental & 5 & $\mathrm{~L}$ & solid & Schwannoma & 150 & 2 & 4 \\
\hline 9 & $32 / \mathrm{F}$ & Chest pain (7) & 4.5 & $\mathrm{R}$ & solid & Schwannoma & 180 & 3 & 6 \\
\hline 10 & $50 / \mathrm{M}$ & Incidental & 5 & $\mathrm{R}$ & solid & Schwannoma & 190 & 3 & 4 \\
\hline 11 & $58 / \mathrm{F}$ & Incidental & 4 & $\mathrm{R}$ & solid & Schwannoma & 140 & 3 & 5 \\
\hline
\end{tabular}


The chest tubes came out on the second or third day; and the average hospital stay was 5.6 days (range: 4 -6). No hospital deaths or major complications were noted. One (Patient 1; Table 1) patient had Horner's syndrome which resolved over 6 months. One other (Patient 7; Table 1) had superficial wound infection and another (Patient 9; Table 1) had postoperative chest infection: both got better with treatment. All patients were clinically followed up for at least 4 months (maximum 18 months). No X-ray evidence of recurrence was found until the last follow up for each patient (Figure 5).

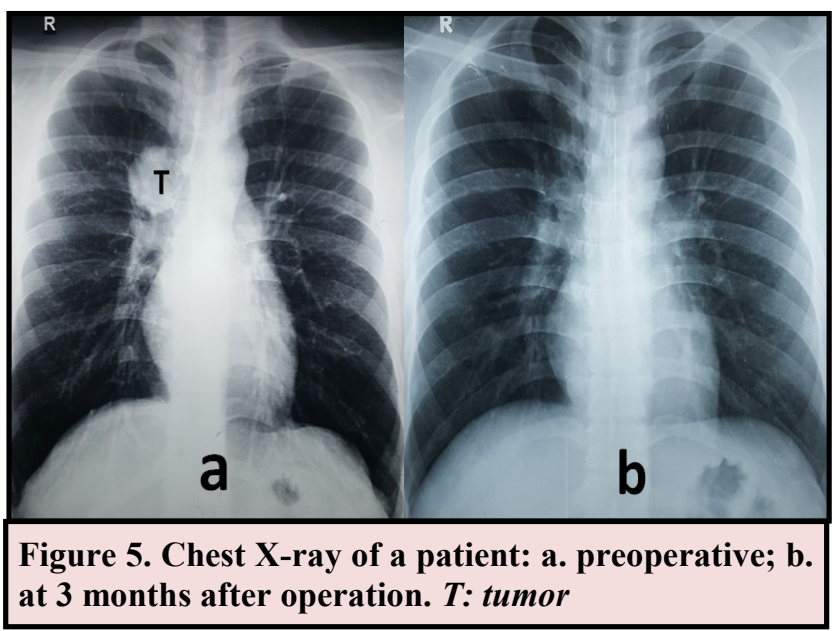

\section{DISCUSSION}

Ninety-five percent of the posterior mediastinal masses are neurogenic tumors; $95 \%$ of them are benign and $95 \%$ of the intrathoracic neurogenic tumors are in the posterior mediastinum. ${ }^{5}$ In the late 1990 's, surgeons used to report their hesitations in choosing thoracoscopic surgery over thoracotomy for treatment of mediastinal masses in general. However, when only posterior mediastinal masses were considered, there was already a growing acceptance for the minimally invasive procedure. ${ }^{4,5}$ Part of the reason, as noted above, is that a posterior mediastinal mass is more likely to be a benign neurogenic tumor than otherwise. The advantages of thoracoscopy over thoracotomy (less access trauma, less disruption of immune function, less pain, shorter stay, and rapid recovery) have been extensively described. ${ }^{3-8}$ Moreover, as most of these patients tend to be younger, as was also demonstrated in this report; cosmetic benefit can also be a potential credit. Posterior mediastinal tumors are mostly asymptomatic, and are thus incidentally found. They are generally more common in younger population, and females. ${ }^{5,7}$ Our observation has, too, been similar in all these respects. Also, our experience reaffirms the preponderance of schwannoma amongst these lesions. $^{8}$ Is preoperative tissue diagnosis mandatory? Generally these tumors, in the absence of features like bone erosion, pleural or lung nodules or pleural effusion, and with a wellmaintained fat plane with surrounding structures, can be safely assumed to be non-malignant. Moreover, the cytological or histological diagnosis is difficult to achieve in the samples, for reasons mentioned earlier. ${ }^{4,8}$ But caution should be practiced in dealing with symptomatic patients, those with history of concurrent or past malignancies and in those with doubtful radiologic features. Kim et al and others have reported about lessons learned from assuming all posterior mediastinal tumors to be neurogenic. ${ }^{9,19}$ All the patients in our series were 'cleared' from a multidisciplinary meeting with the radiologists, and hence a need for preoperative tissue diagnosis. Notably, one patient had a few attempts at needle aspiration before presenting to us. Minimally invasive thoracic surgery is shifting from 3-port to 2-port to a single-port approach, for both pulmonary and mediastinal surgeries. ${ }^{2,10,11}$

Nevertheless, some even advocate adding a fourth port for additional traction. ${ }^{10}$ However, the 'standard' 3 ports have been both, necessary and adequate for us. The tumor-size threshold is also a debated topic in thoracoscopic surgery. While traditionally a cut-off value of $4 \mathrm{~cm}$ has been agreed upon, it has been largely derived from the experience with transcervical thymectomy. ${ }^{10}$ As experience grew, different cut-off values like $6 \mathrm{~cm}$ or $8 \mathrm{~cm}$ have been proposed. ${ }^{4,12,13}$ In any case, common sense dictates that extending the anterior port to a small 'utility' incision would still be preferred to a full thoracotomy, as long as the extension is not so large as to offset the benefits of thoracoscopic approach. We generally dilate the anterior port and deliver the tumor under vision with moderate force, but we do not hesitate to extend the incision slightly in need. Dumbbell tumors are said to account for $10 \%$ of posterior mediastinal tumors ${ }^{16}$, comparable to our finding (1 out of 11). With regards to their excision, there are pros and cons of doing thoracoscopy first. ${ }^{4,8,12,14-16}$

We stick to the traditional laminectomythoracoscopy approach, as this, in our view, is more justified. This allows us to remove the tumor en-bloc; it allows us to evaluate the hemostasis towards the 'spinal end' of dissection. Moreover, it avoids the traction-effect on the spinal cord during thoracic dissection. Operative durations have been variously reported, ranging from $83.5 \mathrm{~min}$ to 270 min on average. ${ }^{5,17,18}$ Surely a surgical team's 
learning curve has an important bearing on it, and we have realized that ourselves in our current practice. Similarly, our mean chest tube duration, length of hospital stay and incidence of complications have been comparable with published reports. ${ }^{5,8}$

\section{REFERENCES}

1. Roviaro G, Rebuffat C, Varoli F, et al. Videothoracoscopic excision of mediastinal masses: indications and techniques. Ann Thor Surg 1994;58:1679-84.

2. Yu PSY, Ng, CSH. Novel perspectives in the surgical treatment of posterior mediastinal masses. J Vis Surg 2018;4:119.

3. Landreneau RJ, Dowling RD, Ferson PF. Thoracoscopic resection of a posterior mediastinal neurogenic tumor. Chest 1992;102:1288-90.

4. $\mathrm{Ng} \mathrm{CSH}, \mathrm{Yim}$ APC. Technical advances in mediastinal surgery: videothoracoscopic approach to posterior mediastinal tumors. Thor Surg Clin 2010;20:297-309

5. Zhang Z, Leiu D, Guo Y, et al. Preferred surgical procedure for posterior mediastinal tumors. Thoracic Cancer 2012;3:68-71.

6. Demmy TL, Krsna MJ, Detterbeck FC, et al. Multicenter VATS experience with mediastinal tumors. Ann Thor Surg 1998:66:187-92.

7. Cardillo G, Carleo F, Khalil MW, et al. Surgical treatment of benign neurogenic tumors of the mediastinum: a single institution report. Eur J Cardiothorac Surg 2008;34:1210-14.

8. Chen X, Ma Q, Wang S, et al. Surgical treatment of posterior mediastinal neurogenic tumors. J Surg Oncol 2019;(1-7).

9. Kim S, Yoo B, Baaj A, et al. Resection of a posterior mediastinal mass: lessons learned from a failed exploration for presumed schwannoma. J Thorac Cardiovasc Surg 2016;152:e75-7.

10. Marshall MB, Demarchi L, Emerson DA, et al. Video-assisted thoracoscopic surgery for complex mediastinal mass resections. Ann Cardiothorac Surg 2015;4(6):509-18.

\section{CONCLUSIONS}

Most posterior mediastinal tumors are benign neurogenic tumors. In the treatment of patients with these tumors, thoracoscopic surgery is feasible, safe and acceptable.
11.Wu CY, Heish MJ, Wu CF. Single-port VATS mediastinal tumor resection: Taiwan experience. Ann Cardiothorac surg 2016;5(2):107-11.

12.Liu Hp, Yim AP, Wan J, et al. Thoracoscopic removal of intrathoracic neurogenic tumors: a combined Chinese experience. Ann Surg 2000;232:187-90.

13. Riquet M, Mouroux J, Pons F, et al. Videothoracoscopic excision of thoracic neurogenic tumors. Ann Thor Surg 1995;60:943-6.

14.Kan P, Schmidt MH. Minimally invasive thoracoscopic resection of paraspinal neurogenic tumors: technical case report. Neurosurgery 2008;63(1 Suppl 1):ONSE54.

15. Valieres E, Findlay M, Fraser RE. Combined microneurosurgical and thoracoscopic removal of neurogenic dumbbell tumors. Ann Thor Surg 1995;59:469-72.

16. Heltzer JM, Krsna MJ, Aldrich F, et al. Thoracoscopic excision of a posterior mediastinal 'dumbbell' tumor using a combined approach. Ann Thor Surg 1995;60:431-3.

17.Cansever L, Kocaturk AI, Cinar HU, et al. Benign posterior mediastinal tumorsresults of a comparative study into video=assisted thoracic surgery and thoracotomy (13 years' experience). Thorac Cardiovasc Surg 2010;58:473-5.

18.Bousamra M, Haasler GB, Paterson GA, et al. A comparative study of thoracoscopic vs open removal of benign neurogenic mediastinal tumors. Chest 1996;109:1461-5.

19. Silver JM, Losken A, Young AN, et al. Ewing's sarcoma presenting as a posterior mediastinal mass: a lesson learned. Ann Thor Surg 1999;67:845-7.

Citation: Sapkota R, Sayami P. Thoracoscopic Surgery for Posterior Mediastinal Mass: Our Initial Experience. JCMS Nepal. 2019; 15(2):75-9. 